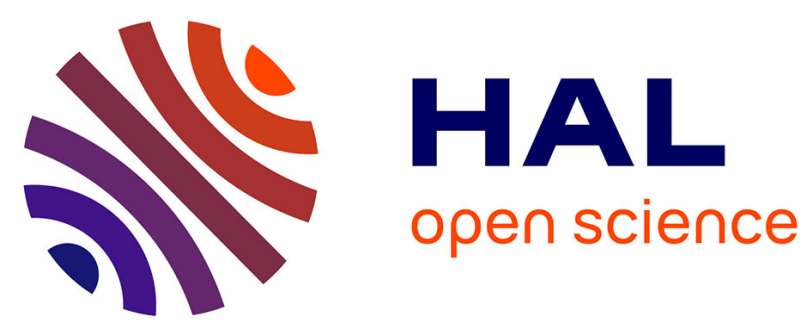

\title{
Research and Application on Protected Vegetables Early Warning and Control of Mobile Client System
}

\author{
Guogang Zhao, Haiye Yu, Lianjun Yu, Guowei Wang, Yuanyuan Sui, Lei \\ Zhang, Linlin Wang, Jiao Yang
}

\section{- To cite this version:}

Guogang Zhao, Haiye Yu, Lianjun Yu, Guowei Wang, Yuanyuan Sui, et al.. Research and Application on Protected Vegetables Early Warning and Control of Mobile Client System. 9th International Conference on Computer and Computing Technologies in Agriculture (CCTA), Sep 2015, Beijing, China. pp.155-162, 10.1007/978-3-319-48354-2_16 . hal-01614218

\author{
HAL Id: hal-01614218 \\ https://hal.inria.fr/hal-01614218
}

Submitted on 10 Oct 2017

HAL is a multi-disciplinary open access archive for the deposit and dissemination of scientific research documents, whether they are published or not. The documents may come from teaching and research institutions in France or abroad, or from public or private research centers.
L'archive ouverte pluridisciplinaire HAL, est destinée au dépôt et à la diffusion de documents scientifiques de niveau recherche, publiés ou non, émanant des établissements d'enseignement et de recherche français ou étrangers, des laboratoires publics ou privés. 


\title{
Research and Application on Protected Vegetables Early Warning and Control of Mobile Client System
}

\author{
Guogang Zhao ${ }^{1,2, a}$, Haiye $\mathrm{Yu}^{1,2, \mathrm{~b}, *}$,Yu Lianjun ${ }^{4, \mathrm{c}}$, Guowei Wang ${ }^{1,2,3, \mathrm{~d}}$, Yuanyuan \\ Sui $^{1,2, \mathrm{e}}$, Lei Zhang ${ }^{1,2, \mathrm{f}}$, Wang Linlin ${ }^{1,2, \mathrm{~g}}$, Jiao Yang ${ }^{3,5, \mathrm{~h}}$ \\ ${ }^{1}$ College of Biological and Agricultural Engineering, Jilin University,Changchun 130022,China; \\ ${ }^{2}$ Key Laboratory of Bionic Engineering,Ministry of Education,Changchun 130022,China; \\ ${ }^{3}$ School of Information Technology, Jilin Agricultural University, Changchun 130118,China; \\ ${ }^{4}$ Changchun City Academy of Agricultural Sciences, Changchun 130111, China; \\ ${ }^{5}$ Sixth Middle School in Changchun, Changchun 130000,China; \\ aahaoguogang2000@qq.com, bhaiye@jlu.edu.cn, ${ }^{c} 120142901 @ q q . c o m$,

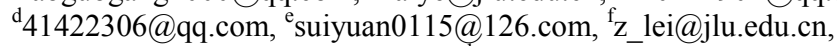 \\ gwangl11211@foxmail.com, ${ }^{\mathrm{g}} 61516131 @ q q . c o m$,
}

\begin{abstract}
Experimental vegetable production is greatly influenced by many environmental factors. There is urgent need to supervise its air temperature and humidity, soil temperature and humidity in the facilities information such as real-time monitoring, and timely early warning and control, in case of irreparable damage. This paper adopts the IOT technology to design and develop mobile client system which is used to make warnings and protect vegetables in order to realize real-time monitoring in the process of vegetable production in the aspects of timely warning of environmental information and control.
\end{abstract}

Keywords: protected vegetables, the internet of things, early warning, control system, mobile client terminal

\section{Introduction}

In protected vegetables production,when the light is few,light intensity weak, day and night temperature differ, relative humidity of air is high and air flow is not good (slow speed), or soil temperature and humidity is too high or too low, they have an effect on the normal growth and development of vegetable crops. At present, in the regulation and control of greenhouse, there are man-made management which means poor regulatory capacity,awful management, bad proportion of the input-output to cause final low economic rewards. If we want to get the normal condition for growth and development of protected vegetables, it is necessary to regulate environmental factor timely and scientifically which may possibly affect the growth of vegetables in the greenhouse to meet the need for the development of vegetable. 
Internet of thing has a perception as its premise to realize fully interconnected networks between man and man,man and material or substances[1-4]. Agricultural internet of thing makes use of the sensor to obtain environmental date through a variety of instruments to monitor real-time display or control the parameters which are involved in to ensure a great harvest in the aspects of the crops,livestock and poultry. At presence, foreign counterparts have widely adopted sensor of agricultural things of internet in the seeding,production,transportaion and storage,etc. Moreover, they have accomplished the successful monitoring in the aspects of packaging and irrigation and Chinese scholars have made initial achievement at home[5-10].

When we set up the system to monitor vegetable for early warning and control, most of people could not keep the computer next all the time which often caused the huge damage. However, mobile phones are often carried with you every second. The problem is solved by the establishment of a monitoring and control system based on the mobile client's facilities effectively.

\section{System design}

\subsection{System framework}

The system makes use of $\mathrm{c} / \mathrm{s}$ model to achieve the service mode of multi-clients sharing data.Taking advantage of WCF,receiving and storing,sending data can be realized.The main framework of the system[11-16] is shown in Figure1. 


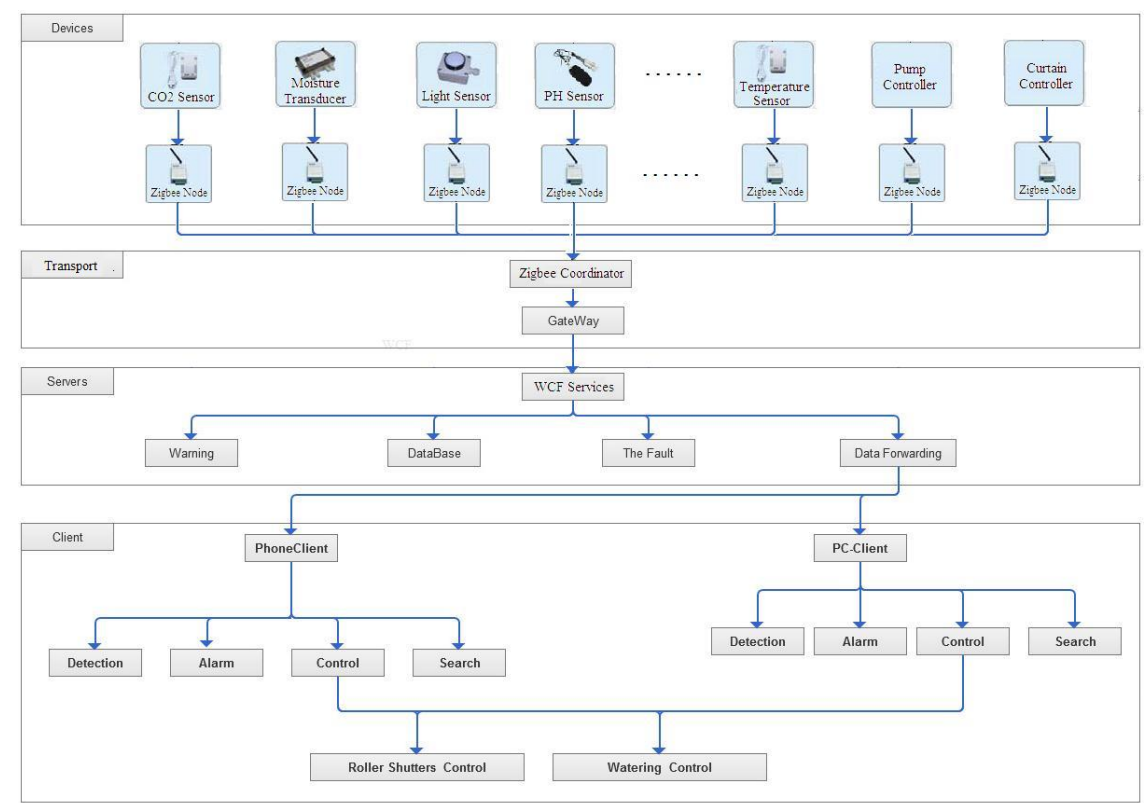

Fig. 1. The overall architecture of the system

\subsection{Technology adopted}

2.2.1Storage for remote data

In the system, the data transmission of the sensor is not regular. It may send a message to the server at any time. If the server acts as a connection to the remote and meanwhile needs to do a lot of I/O storage, the process will has a greater impact on database performance so as to influence the functional performance of the system. Therefore, this system tries to establish a specific database server which can alleviate slow performance effects caused by I/O storage.

2.2.2 Server balanced loading

Considering the future promotion of the system, if the data acquisition and equipment control were done in thousands of greenhouses, a steep pressure phenomenon may bring the slow response of the server, denial of server or system crashes and other issues.In order to prevent the occurrence of the problems, this system uses the NAT load balancing method, which means an external IP address is mapped into a plurality of internal IP addresses for each connection to convert every connection requirement to an address of an internal server dynamically,and meanwhile the external connection request is introduced to the server which is converted to the address to achieve the purpose of loading balancing.

\subsubsection{WCF server}

Windows communication foundation(WCF) is developed by Microsoft company as application interfaces of a set of data communication.WCF communication mode mainly has three kinds of simple request reply: simple request-reply mode;no replay 
model and double-replies mode(that is data communication happening between clients and server sensors who can send the message to the clients at the same time.)this system presents the last model to realize the data communication between client terminals and servers, between transmission terminals and severs and between control equipment and servers.

\subsubsection{Automatic detection of server}

This gateway system with a remote hardware client and the sensor is used in TCP/IP protocol.This is a long chain with each communication at least maintained by a connection. They are not the system resources to be saved.when the client is using a proxy,even if the client communication with the server channel breaks, the servers can not capture the information so that the client has been out of connection with the server while the server still helps client to maintain this communication, which caused the huge waste of resources. Therefore, the system uses the heartbeat program that is server sends a data package to every communication client from time to time.If packets fail, it will continuously try to send three times.If they all failed then the system will recover resources greatly to improve utilization rate of resource.

\subsection{System control process}

The sensor transmits the data to the control center through the LTE gateway and after that,control center after processing sent the warning data to the mobile phone user.Mobile phone user get early warning data and send control information to the control center. The control center will convert control information into commands to send to the LTE node in order to achieve the equipment control.

\subsection{Data communication protocol}

Data communication is important for the communication between the two parties in the network. Actual line in the internet needs to realize the communication with a hardware device or the server and the clients terminals to ensure the smooth running of the whole system. There are two kinds of main data communication format in this paper, a kind of is the data collected by the sensor, the collected data is sent to the server; another is the control data, the server receives from mobile client's instructions, and instructions are sent to the need to control the device. The data communication protocol is shown in table 1 .

Table 1. Data communication

\begin{tabular}{ccc}
\hline Type & Equipment & Data communication \\
\hline monitor & Collect & num-time-airt1-airt2-airh-soilt1-soi1t2-soilh \\
\hline Control & Water pump & num-priority-state \\
\hline & Rolling machine & num-priority-state \\
\hline
\end{tabular}




\section{System realization}

\subsection{Data collection}

System can receive data from sensors and analyze received data by data protocol parsing as text displayed in cell phone client window.As shown in Figure2

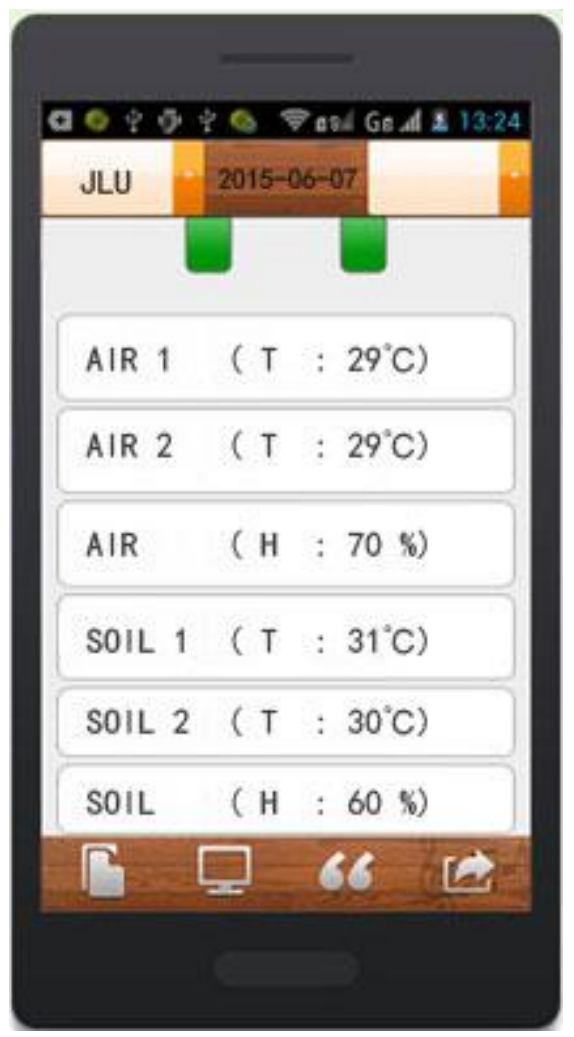

Fig. 2. Date collecting

\subsection{Early warning}

When the various aspects of environment for growing crop changed over a given threshold value(the threshold's set up shown in Figure3) the system will automatically alarm and notify the user in the form of sound and vibration to show temperature and humidity greater than warning value data information and hence prompt the user to grasp the real-time to control the environment of the greenhouse condition and control the corresponding equipment to protect crops in better environment. 


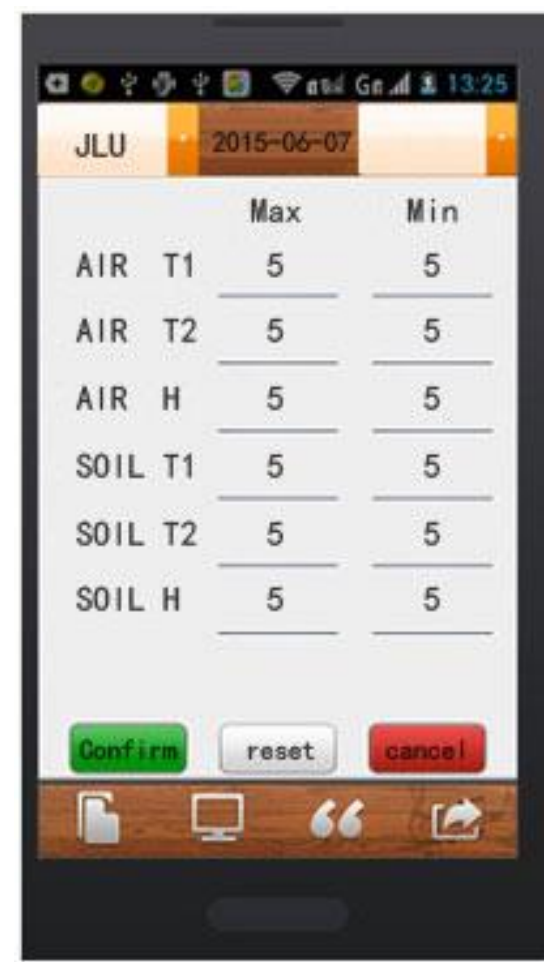

Fig. 3. Threshold settings

\subsection{Device control}

When the environmental information exceeds the threshold, the system can manually realize the straight control to the equipment (pump roller shutter) to achieve the timely control of the environment.As shown in figure 4 of the device control interface: 


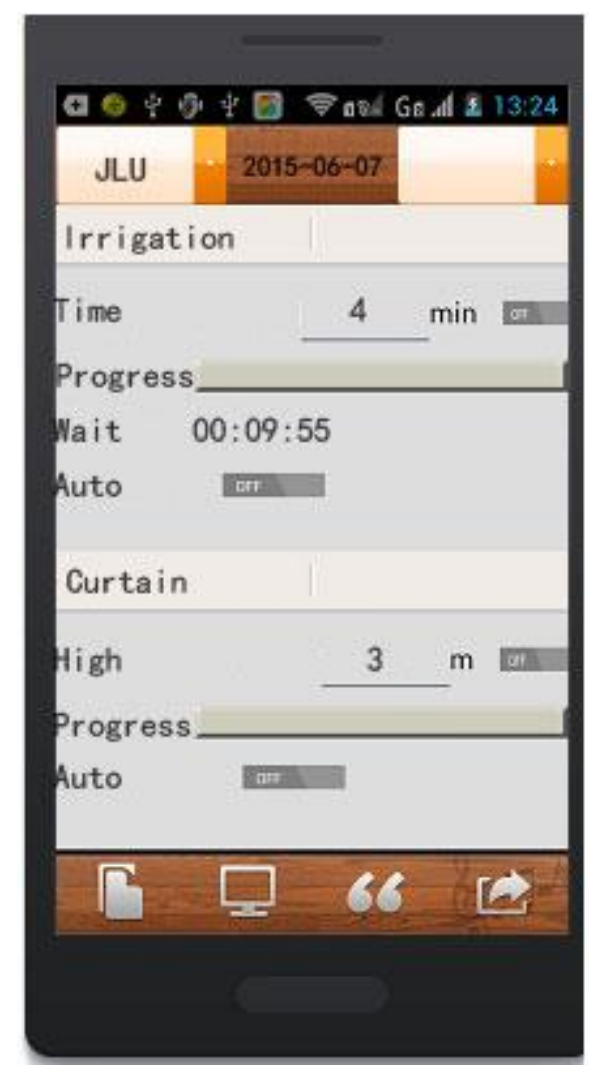

Fig. 4. Device control

\section{Conclusions}

The paper adopts Web Services technique to explain the service of data collection,storage, early warning, controlled and provide the interface for clients and date communication; it mainly makes use of the IOT technology through the wireless network to achieve the communication between hardware and hardware for smooth data communication; also, it applies language and database to achieve facilities and vegetables and remote control of the mobile phone client software. Thus this paper solves the time and space limit of data acquisition and control. After testing, if the sensor sends a data every ten minutes, environmental data can be received within zero point one seconds. When the phone after sending a control command, equipment can work within zero point one.

The system has been running for nearly a year in Jilin Province, and it has played an effective role in regulating the quality and yield of greenhouse crops. 


\section{Acknowledgment}

Funds for this research was provided by National 863 subjects (2012AA10A5064, 2013AA103005-04), Jilin province science and technology development projects(20110217), China Postdoctoral Science Foundation the 54th surface funded(2013M541308), Jilin University Young Teachers Innovation Project (450060491471).

\section{References}

1. CHEN Hai-Ming, CUI Li, XIE Kai-Bin. chinese journal of computer [J]. Institute of Computing Technology, Chinese Academy of Sciences, Beijing, 2013,36(1):168-188

2. SUN Qi-bo, LIU Jie, LI Shan et al. Internet of Things: Summarize on Concepts, Architecture and Key Technology Problem[J]. Journal of Beijing University of Posts and Telecommunications,2010,33(3):1-9

3. HU Yong-Li, SUN Yan-Feng, YIN Bao-Ca, Information Sensing and Interaction Technology in Internet of Thing[J]. chinese journal of computers, 2012, 35(6): 1147-1162.

4. CHENG Man, WANG Rang-hui, Advance in Technical Research and Application of Internet of Things[J]. Geomatics World, $2010: 22-27$.

5. Li Zhenfa, Wang Tie, Gong Zhihong, et al. Forewarning technology and application for monitoring low temperature disaster in solar greenhouses based on internet of things[J]. Transactions of the Chinese Society of Agricultural Engineering (Transactions of the CSAE), 2013, 29(4): $229-236$

6. Sheng Ping, Guo Yangyang, Li Pingping. Intelligent Measurement and Control System of Facility Agriculture Based on ZigBee and 3G[J]. Transactions of the Chinese Society for Agricultural Machinery, 2012, 43(12): 229-233.

7. Yan Xiaojun, Wang Weirui, Liang Jianping. Application mode construction of internet of things (IOT) for facility agriculture in Beijing[J]. Transactions of the CSAE, 2012, 28(4): $149-154$.

8. Wang Mao-Hua, The Internet of things in agriculture application development demand for modern scientific instruments[J], Modern Scientific Instruments, 2010 ( 3) : 5- 6.

9. ZHOU Xiao-Bo. Facility Agriculture Online Monitoring System Based on Internet of Things[J]. Journal of Taiyuan University of Science and Technology, 2011,32(3):182-184.

10. Ge Wenjie, Zhao Chunjiang. State-of-the-art and Developing Strategies of Agricultural Internet of Things[J]. Transactions of the Chinese Society for Agricultural Machinery, 2014,45(7):222-230. 
11. HANXu, WANG Hai-bo, LIU Ke-jun. Service-oriented SOA Middleware Design Based on .NETFramework WCF Component[J], Journal of Chinese Computer Systems, 2010,31(12):2359-2364.

12. TAN Qi. web Application Research Based on WCF Services Framework and Silverlight[J]. Computer and Modernization, 2011(1):79-81.

13. QIAN Tao. Design and Implementation of Computer Lab Management System Based on WCF[j]. Computing Technolog y and Automa tion. 2010, 29(4):135-137.

14. ZHAO Ming, ZHANG Xu, XIONG Jing. Research of vivil aviation reservation system based on .NET and WCF[J] . 2012, 33(4):1653-1659.

15. Li Yan,Guowei Wang, Shuifang Wu.Facilities vegetables monitoring and control system design based on WCF and Internet of things.Advanced Materials Research . 2014:26372640 .

16. Li Yan, Dejiang Hao, Hao Zhang.The Facilities Vegetables Warning and Control System Based on Mobile Phone SMS.Applied Mechanics and Materials 2014: 576-579. 